\title{
The Association of Thyroid Function and Heart Valve Sclerosis. Results from a Population-Based Study
}

\author{
MARCUS DÖRR, JöRG RUPPERT, HENRI WALLASCHOFSKI*, STEPHAN B. FELIX AND HENRY VÖLZKE** \\ Department of Internal Medicine B, Cardiology, Angiology and Pulmology, Ernst-Moritz-Arndt-University, Greifswald, Germany \\ *Department of Internal Medicine A, Endocrinology and Gastroenterology, Ernst-Moritz-Arndt-University, Greifswald, Germany \\ **Institute of Epidemiology and Social Medicine, Ernst-Moritz-Arndt-University, Greifswald, Germany
}

\begin{abstract}
Objectives: Thyroid dysfunction is associated with detrimental cardiovascular effects. We analyzed whether thyroid status is associated with aortic valve sclerosis (AVS) and mitral annular calcification (MAC) as markers of generalized atherosclerosis. Design: Data of 2065 subjects ( 923 women and 1142 men) aged $\geq 45$ years from the Study of Health in Pomerania (SHIP) were analyzed with respect to low, medium and high TSH levels. Logistic regression models were adjusted for major confounders of atherosclerosis. Main outcome: In women, the prevalence of AVS was the highest in those with low TSH $(35.1 \%$ vs. $26.7 \%$ in medium TSH; $<<0.05)$, while there was a higher prevalence of MAC in men with high TSH levels $(9.2 \%$ vs. $5.2 \%$ in medium TSH; $\mathrm{p}<0.05)$. Compared with euthyroid men there was an increased adjusted odds ratio for MAC (OR 2.07; 95\% CI 1.12-3.89, p<0.05), for the combination of AVS and MAC (OR 2.13; 95\% CI $1.08-4.21, \mathrm{p}<0.05)$ or for one of both (OR 1.47; 95\% CI 1.02-2.13, $\mathrm{p}<0.05$ ) among men with high TSH. No such association was found in women. Conclusions: There was an association between thyroid function and valvular sclerosis. Men with high TSH values had increased odds for AVS or MAC, and the combination of both. These findings may reflect an increased atherosclerotic state in affected subjects.
\end{abstract}

Key words: Thyroid dysfunction, Hypothyroidism, Heart valve sclerosis, Atherosclerosis, Study of Health in Pomerania

(Endocrine Journal 55: 495-502, 2008)

AORTIC valve sclerosis (AVS) and mitral annular calcification (MAC) are each linked to cardiovascular risk factors [1,2]. Pathohistologically, early lesions represent the summation of degenerative and inflammatory processes that are similar to the development of atherosclerosis, resemble atherosclerotic plaques, and are characterized by lipid and calcium deposition in the valve annular fibrosa [3]. Thus, AVS and MAC are independently associated with atherosclerotic diseases $[2,4-6]$.

A linkage between thyroid function and alterations of the cardiovascular system has been generally accepted [7]. Many of the thyroid hormone effects are at least

Received: October 7, 2007

Accepted: January 7, 2008

Correspondence to: Marcus DÖRR, M.D., Department of Internal Medicine B, Ernst Moritz Arndt University, Friedrich Loeffler Str. 23 a, D-17475 Greifswald, Germany potentially associated with increased cardiovascular morbidity and mortality. However, the possible linkage of thyroid dysfunction and valve sclerosis has not been investigated so far, although it might be regarded as pathophysiologically plausible. For example hypothyroidism is associated with an increased risk of atherosclerosis [8], while hyperthyroidism may even exert protective effects against atherosclerosis and atherosclerotic diseases $[9,10]$. Taking into consideration that AVS and MAC are markers of an increased cardiovascular and all-cause mortality [5, 11, 12], a possible association between valve sclerosis and thyroid dysfunction might at least in part explain the elevated cardiovascular mortality reported in thyroid dysfunction [13-15].

Therefore, the aim of the present study was to determine whether thyroid function status is associated with AVS and MAC in a population-based sample. 


\section{Method}

\section{Study population}

The Study of Health in Pomerania (SHIP-0) is a cross-sectional study in the northeastern area of Germany, West Pomerania. A sample from the population aged 20 to 79 years was drawn using population registries. Finally, 7008 subjects were sampled, with 292 randomly selected persons of each sex in each of the twelve 5-year age strata. The net sample (without migrated or deceased persons) comprised 6267 eligible subjects. The SHIP-0 sample comprised 4310 participants ( $68.8 \%$ of eligible subjects). Data were collected between October 1997 and May 2001. All participants gave informed written consent. The study was approved by the Ethics Committee of the University of Greifswald.

In the SHIP-0 population, only participants aged $\geq 45$ years $\quad(n=2517)$ received echocardiographic examination. Seven individuals who refused echocardiography, 151 with uncertainty regarding the echocardiographic valve assessment, 10 with a prosthetic valve, 259 subjects with known thyroid disease or with uncertainty regarding a present thyroid disease, and 25 for whom no values of serum TSH were available were excluded from analyses. This resulted in a final study population of 2065 subjects who were available for the present analysis.

\section{Clinical evaluation}

Potential confounder variables were selected for the analyses. From the interview, we included the following: age, sex, school education $(<10, \geq 10$ years; categorization on the basis of the organization of the East German school system), smoking (never, ex-smoker, current smoker), pack years, diabetes mellitus, past myocardial infarction, and stroke. Systolic and diastolic blood pressure was measured three times in seated subjects after a 5 minute rest period, with each reading being followed by a further rest period of 3 minutes. Mean blood pressure was calculated. Pulse pressure was defined as the difference between mean systolic and diastolic measurements. We further selected body mass index (BMI; $\mathrm{kg} / \mathrm{m}^{2}$ ). Information on medication was recorded by a computer-aided method using the anatomic, therapeutic and chemical code (ATC). Information on antidiabetic drugs (anatomical-therapeutic- chemical [ATC] code A10), aspirin (ATC codes $\mathrm{B} 01 \mathrm{AC}$ and N02BA01), antihypertensive drugs (ATC code $\mathrm{C} 02, \mathrm{C} 07, \mathrm{C} 08$, and $\mathrm{C} 09$ ), and lipid-lowering drugs (ATC code C10AA) was used for the analysis. Serum TSH was analyzed by immunochemiluminescent procedures (LIA-mat, Byk Sangtec Diagnostica $\mathrm{GmbH}$, Frankfurt, Germany). The functional sensitivity of the TSH assay was $0.03 \mathrm{mIU} / \mathrm{L}$. Levels of serum TPO-antibodies (TPOAb) were measured by an enzyme immunoassay (VARELISA, Elias Medizintechnik GmbH, Freiburg, Germany). The functional sensitivity of this assay was $1 \mathrm{IU} / \mathrm{mL}$. The upper reference limit was $60 \mathrm{IU} / \mathrm{mL}$ for men and $100 \mathrm{IU} / \mathrm{mL}$ for women. The TPOAb status was defined as positive, if values were greater than $200 \mathrm{IU} / \mathrm{mL}$. Other serological parameters included into the analysis were hemoglobin $(\mathrm{Hb}) \mathrm{A} 1 \mathrm{C}(\%)$, fibrinogen $(\mathrm{g} / \mathrm{L})$, and non-fasting cholesterol (mmol/L), HDL-C (mmol/L), LDL-C (mmol/L), and lipoprotein $(\mathrm{a})(\mathrm{mg} / \mathrm{dL})$.

\section{Echocardiography}

Two-dimensional, M-mode, and Doppler echocardiography was performed using the Vingmed CFM 800A system (GE Medical Systems, Waukesha, Wis., USA) without knowledge of other clinical data of participants. Aortic and mitral valves were scanned from the parasternal short and long axes and the apical 2-, 4- and 5-chamber views. AVS was characterized by an abnormal irregular thickening and a focal or diffuse increase of the echogenicity of the leaflets with or without reduced systolic opening. MAC was identified by the presence of bright echoes at the junction of the atrioventricular groove and posterior mitral leaflet. All measurements of intra-reader, intra-observer, interreader and inter-observer agreements revealed Spearman correlation coefficients of $>0.85$ and differences in mean $( \pm 2 \mathrm{SD})$ of $<5 \%(<25 \%)$.

\section{Statistical analyses}

Data on quantitative characteristics are expressed as means $\pm \mathrm{SD}$. Data on qualitative characteristics are expressed as percent values or absolute numbers as indicated. For analysis, participants were divided into 3 groups according to the sex-specific quintiles of TSH levels: low ( $1^{\text {st }}$ quintile; $<0.37 \mathrm{mIU} / \mathrm{L}$ in women, $<0.35 \mathrm{mIU} / \mathrm{L}$ in men $)$, medium $\left(2^{\text {nd }}\right.$ to $4^{\text {th }}$ quintile; $0.37-1.02 \mathrm{mIU} / \mathrm{L}$ in women, $0.35-0.92 \mathrm{mIU} / \mathrm{L}$ in men) 
and high $\left(5^{\text {th }}\right.$ quintile; $>1.02 \mathrm{mIU} / \mathrm{L}$ in women, $>0.92$ $\mathrm{mIU} / \mathrm{L}$ in men) TSH. All analyses were performed for men and women separately. The frequencies of AVS and/or MAC with respect to thyroid function status were compared by the $\chi^{2}$-test. Thereafter, data were dichotomized with respect to valve sclerosis (dependent variable: MAC and/or AVS) and were analyzed by logistic regression models. The adjusted odds ratio (OR) with its $95 \%$ confidence interval (CI) was calculated. Various models were created stepwise by considering determinants of valve sclerosis. The full model controlled for age, BMI, pulse pressure, prior myocardial infarction, diabetes mellitus, serum fibrinogen, smoking status, education status, and medication with ACE inhibitors, AT-II antagonists, and statins. Other variables (including total cholesterol, LDL cholesterol, HDL cholesterol, lipoprotein (a), and medication with salicylic acid) did not lead to $>5 \%$ change in the coefficient of interest. A value of $\mathrm{p}<0.05$ was considered statistically significant. Analyses were performed with SPSS software version 14.0.1 (SPSS Inc., Chicago, IL, USA).

\section{Results}

\section{Characteristics of participants}

923 women and 1142 men aged $\geq 45$ were included in the analyses (mean age $61.7 \pm 9.6 \mathrm{yrs}$ ). Among the total study population 423 subjects $(20.4 \%)$ had low, 1234 (59.8\%) medium, and 408 (19.8\%) high serum TSH values. Compared to those with medium TSH, women with low TSH were older (Table 1). Among both gender, those with high serum levels had higher TPOAb serum levels as wells as a higher prevalence of $\mathrm{TPOAb}$ positivity in comparison to medium TSH levels. Furthermore, men with low TSH had slightly higher plasma fibrinogen levels and lower total cholesterol levels than those with medium TSH (Table 1). Further baseline characteristics with respect to gender and thyroid function are presented in (Table 1).

\section{Association between serum TSH levels and valve sclerosis}

Among women, the unadjusted prevalence of AVS was highest in those with low TSH levels, while there was a statistically higher prevalence of MAC in men with high TSH levels $(\mathrm{p}<0.05$ versus medium TSH) (Fig. 1). The frequencies of MAC increased continuously with TSH values in women and from the low to the high TSH group in men ( $p<0.05$; Fig. 1).

Logistic regression analyses revealed a tendency towards a higher risk of AVS in men with high TSH levels compared to those with medium TSH levels (OR 1.38; 95\% CI 0.96-1.99; p=0.08) (Fig. 2a). Further analyses demonstrated that men with high TSH levels had an increased odds for MAC (OR 2.07; 95\% CI 1.12-3.89; $\mathrm{p}=0.02$ ) (Fig. 2b), AVS or MAC (OR 1.47; 95\% CI 1.02-2.13; $\mathrm{p}=0.04$ ) (Fig. 4c), as well as for the combination of AVS and MAC (OR 2.13; 95\% CI $1.08-4.21 ; p=0.03$ ) (Fig. 2d). In contrast, such associations were not found in women (Fig. 2b-d).

\section{Sensitivity Analyses}

Inclusion of subjects with known or uncertainty regarding thyroid disease as well as exclusion of persons receiving drugs known to influence progression of heart valve sclerosis (ACE inhibitors, AT-II antagonists, statins) yielded similar results. Likewise, consideration of TPOAb status did not modify the statistical models and therefore was not included in the final analyses. Additional sensitivity analyses were done using varying cut-offs for defining low and high serum TSH levels. These analyses did not change the main results. For example, when the lower limit of TSH was defined $<0.4 \mathrm{mIU} / \mathrm{L}$ and the upper limit $>4.0 \mathrm{mIU} / \mathrm{L}$ the $\mathrm{OR}$ for MAC was 10.3 (95\% CI 1.62-65.14; $p=0.013)$ among men. One limitation of these cut-off points was the low number of affected subjects, resulting in large confidence intervals and thus a low precision of the risk estimate.

\section{Discussion}

In the present study we sought to determine the relation of thyroid function status and heart valve sclerosis in a population-based sample of subjects aged 4579 years. After adjustment for major confounders, an increased risk of AVS or MAC, and the combination of both was found in men with high TSH levels. In women such an association was not present. Our findings were stable over a number of sensitivity analyses.

We assume that our results may reflect an association between thyroid function and atherosclerotic state 
Table 1

\begin{tabular}{|c|c|c|c|c|c|c|}
\hline \multirow[b]{2}{*}{ Characteristics } & \multicolumn{3}{|c|}{ Women } & \multicolumn{3}{|c|}{ Men } \\
\hline & $\begin{array}{c}\text { TSH low } \\
{\left[\begin{array}{c}\text { TSH }<0.37 \mathrm{mIU} / \mathrm{L}] \\
191\end{array}\right.}\end{array}$ & $\begin{array}{c}\text { TSH medium } \\
\text { [TSH } 0.37-1.02 \mathrm{mIU} / \mathrm{L}] \\
551\end{array}$ & $\begin{array}{c}\text { TSH high } \\
{\left[\begin{array}{c}\text { TSH }>1.02 \mathrm{mIU} / \mathrm{L}] \\
181\end{array}\right.}\end{array}$ & $\begin{array}{c}\text { TSH low } \\
{\left[\begin{array}{c}\text { TSH }<0.35 \mathrm{mIU} / \mathrm{L}] \\
232\end{array}\right.}\end{array}$ & $\begin{array}{c}\text { TSH medium } \\
\text { [TSH } 0.35-0.92 \mathrm{mIU} / \mathrm{L}] \\
683\end{array}$ & $\begin{array}{c}\text { TSH high } \\
{\left[\begin{array}{c}\mathrm{TSH}>0.92 \mathrm{mIU} / \mathrm{L}] \\
227\end{array}\right.}\end{array}$ \\
\hline $\begin{array}{l}\text { Age (yrs) } \\
\text { Sex (male) }\end{array}$ & $63.3 \pm 9.4^{\dagger}$ & $59.8 \pm 9.6$ & $60.8 \pm 9.4$ & $63.3 \pm 9.3$ & $62.3 \pm 9.5$ & $62.1 \pm 9.9$ \\
\hline School education. $<10$ years (\%) & $66.0^{\dagger}$ & 53.7 & $59.1^{\dagger}$ & 63.8 & 59.8 & 56.4 \\
\hline Smoking status & & & & & & \\
\hline Never-smoker (\%) & 59.2 & 65.3 & 62.4 & 15.9 & 20.9 & 18.5 \\
\hline Ex-smoker $(\%)$ & 19.9 & 20.5 & 23.8 & 60.3 & 54.6 & 62.1 \\
\hline Current smokers (\%) & 20.9 & 14.2 & 13.8 & 23.7 & 24.5 & 19.4 \\
\hline Pack years & $17.1 \pm 14.2$ & $18.3 \pm 12.0$ & $21.3 \pm 9.1$ & $28.5 \pm 22.8$ & $30.8 \pm 16.2$ & $34.8 \pm 13.5$ \\
\hline Diabetes mellitus (\%) & 9.8 & 11.1 & 10.2 & 11.4 & 12.8 & 14.4 \\
\hline Hypertension (\%) & 62.2 & 60.5 & 57.5 & 72.0 & 75.5 & 78.8 \\
\hline Myocardial infarction (\%) & 2.1 & 1.8 & 3.3 & 7.4 & 8.5 & 8.8 \\
\hline Stroke $(\%)$ & 2.6 & 2.2 & 2.2 & 5.2 & 4.7 & 6.2 \\
\hline Body mass index $\left(\mathrm{kg} / \mathrm{m}^{2}\right)$ & $27.8 \pm 5.1$ & $28.1 \pm 5.0$ & $28.9 \pm 5.4$ & $27.7 \pm 3.6$ & $28.1 \pm 3.6$ & $28.6 \pm 4.1$ \\
\hline Waist-hip ratio & $0.82 \pm 0.05$ & $0.82 \pm 0.06$ & $0.82 \pm 0.05$ & $0.95 \pm 0.06$ & $0.95 \pm 0.06$ & $0.95 \pm 0.05$ \\
\hline Blood pressure & & & & & & \\
\hline Systolic (mmHg) & $140.8 \pm 21.6$ & $139.2 \pm 20.3$ & $140.4 \pm 22.2$ & $146.7 \pm 20.8$ & $149.3 \pm 20.7$ & $148.9 \pm 19.7$ \\
\hline Diastolic (mmHg) & $83.9 \pm 9.3$ & $84.3 \pm 10.7$ & $84.4 \pm 10.5$ & $86.9 \pm 12.3$ & $88.0 \pm 11.6$ & $89.2 \pm 11.0$ \\
\hline Puls pressure (mmHg) & $56.9 \pm 17.1$ & $54.8 \pm 15.3$ & $56.0 \pm 16.5$ & $59.7 \pm 15.2$ & $61.3 \pm 15.9$ & $59.7 \pm 15.1$ \\
\hline Heart rate (beats per minute) & $72.5 \pm 11.3$ & $72.1 \pm 11.0$ & $71.4 \pm 10.7$ & $71.4 \pm 12.2$ & $71.9 \pm 13.0$ & $71.9 \pm 12.2$ \\
\hline Medication & & & & & & \\
\hline ACE inhibitors (\%) & 21.5 & 17.6 & 13.8 & 21.6 & 22.5 & 22.0 \\
\hline AT-II antagonists (\%) & 2.6 & 2.4 & 4.4 & 1.7 & 3.4 & 4.8 \\
\hline Statins $(\%)$ & 9.4 & 7.1 & 6.1 & 13.4 & 11.3 & 9.7 \\
\hline Salicylic acid (\%) & 9.4 & 9.4 & 8.8 & 11.6 & 13.5 & 16.3 \\
\hline Laboratory parameters & & & & & & \\
\hline $\mathrm{TSH}(\mathrm{mU} / \mathrm{l})$ & $0.23 \pm 0.10$ & $0.64 \pm 0.17$ & $3.15 \pm 9.11^{*}$ & $0.23 \pm 0.09^{\dagger}$ & $0.60 \pm 0.16$ & $1.79 \pm 4.00^{\ddagger}$ \\
\hline $\mathrm{TSH}(\mathrm{mU} / \mathrm{l})^{*}$ & $0.26(0.16 ; 0.32)$ & $0.62(0.49 ; 0.76)$ & $1.37(1.16 ; 2.02)$ & $0.24(0.17 ; 0.30)$ & $0.58(0.46 ; 0.72)$ & $1.19(1.02 ; 1.51)$ \\
\hline TPOAb (IU/L) & $87 \pm 357$ & $65 \pm 183$ & $235 \pm 585$ & $28 \pm 86^{\ddagger}$ & $34 \pm 122$ & $118 \pm 477$ \\
\hline TPOAb positive $(\%)$ & 8.4 & 9.8 & $23.4^{\dagger}$ & 2.1 & 3.3 & $9.3^{\dagger}$ \\
\hline Fibrinogen $(\mathrm{g} / \mathrm{L})$ & $3.19 \pm 0.68$ & $3.10 \pm 0.65$ & $3.10 \pm 0.64$ & $3.20 \pm 0.85^{\dagger}$ & $3.05 \pm 0.70$ & $3.03 \pm 0.71$ \\
\hline Cholesterol $(\mathrm{mmol} / \mathrm{L})$ & $6.08 \pm 1.14$ & $6.23 \pm 1.20$ & $6.30 \pm 1.19$ & $5.68 \pm 1.12^{\dagger}$ & $5.96 \pm 1.31$ & $6.02 \pm 1.24$ \\
\hline $\mathrm{LDL}-\mathrm{C}(\mathrm{mmol} / \mathrm{L})$ & $3.86 \pm 1.13$ & $3.94 \pm 1.12$ & $3.98 \pm 1.15$ & $3.59 \pm 1.05$ & $3.78 \pm 1.20$ & $3.83 \pm 1.17$ \\
\hline HDL-C (mmol/L) & $1.58 \pm 0.44$ & $1.60 \pm 0.52$ & $1.62 \pm 0.46$ & $1.29 \pm 0.37$ & $1.29 \pm 0.38$ & $1.29 \pm 0.39$ \\
\hline Lipoprotein (a) (mg/L) & $204 \pm 245$ & $191 \pm 216$ & $227 \pm 248$ & $177 \pm 190$ & $177 \pm 213$ & $175 \pm 209$ \\
\hline HbAlc (\%) & $5.6 \pm 1.0$ & $5.6 \pm 0.9$ & $5.6 \pm 0.8$ & $5.7 \pm 0.9$ & $5.8 \pm 1.0$ & $5.8 \pm 1.2$ \\
\hline
\end{tabular}

Values are means \pm SD or percentages. $*=$ mean (interquatile range). $\dagger=p<0.05$ versus medium TSH within gender group (ANOVA of $\mathrm{Chi}^{2}$-test) $\mathrm{TSH}=$ serum thyrotropin; TPOAb $=$ serum TPO-antibodies; LDL-C $=$ low-density lipoprotein cholesterol; HDL-C $=$ highdensity lipoprotein cholesterol.

in male individuals with high TSH levels, taking into account that AVS and MAC both share common risk factors of atherosclerosis $[1,2,4,6]$, and are highly associated with generalized atherosclerosis [6], coronary artery disease [16, 17], myocardial infarction [5], and stroke [4]. In particular MAC is strongly associated with cardiovascular disease $[12,18]$. This has been recently confirmed in 3929 elderly subjects participating in the community-based Cardiovascular Health Study [18]. Subjects exhibiting MAC had an increased risk for myocardial infarction and stroke, respectively [18].
To the best of our knowledge, this the first study to investigate the association of thyroid function with valve sclerosis. Our findings are at least in part in line with previous studies that found an association between hypothyroidism and an elevated risk for coronary artery disease in both males and females $[9,10]$. In contrast, certain cross-sectional studies could not confirm an association of hypothyroid function and atherosclerosis [19-21].

Among our population a significant association between serum TSH levels and valve sclerosis was only 


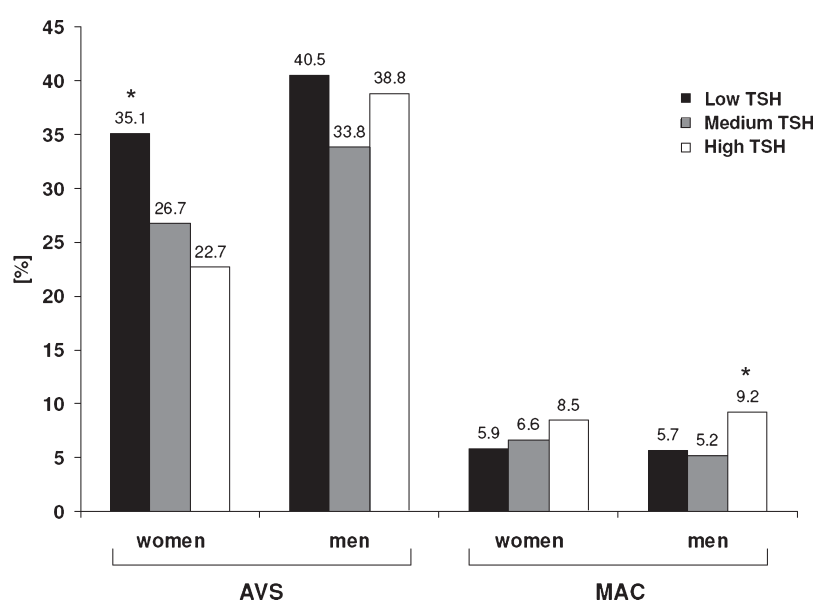

Fig. 1. Unadjusted prevalence of AVS and MAC with respect to gender and serum TSH levels.

Low TSH, $1^{\text {st }}$ sex-specific quintile; $<0.37 \mathrm{mIU} / \mathrm{L}$ in women and $<0.35 \mathrm{mIU} / \mathrm{L}$ in men; medium $\mathrm{TSH}, 2^{\text {nd }}$ to $4^{\text {th }}$ sex-specific quintile: $0.37-1.02 \mathrm{mIU} / \mathrm{L}$ in women and $0.35-0.92 \mathrm{mIU} / \mathrm{L}$ in men; high $\mathrm{TSH}, 5^{\text {th }}$ sex-specific quintile: $>1.02 \mathrm{mIU} / \mathrm{L}$ in women and $>0.92 \mathrm{mIU} / \mathrm{L}$ in men. ${ }^{*} \mathrm{p}<0.05$ versus medium TSH (chi ${ }^{2}$-test). present in men, but not in women. This is in agreement with one previous study showing an association of subclinical hypothyroidism with carotid atherosclerosis in 1434 hyperlipidemic men [22]. On the other hand, we could not confirm other data that reported an association between hypothyroid state and atherosclerosis in women, too. Thus, the cross-sectional Rotterdam Study [23] demonstrated an association between subclinical hypothyroidism and a greater age-adjusted prevalence of radiographic aortic atherosclerosis (OR 1.7; 95\% CI 1.1-2.6) and myocardial infarction (OR 2.3; 95\% CI 1.3-4.0) in women [23]. Likewise, a small casecontrol study showed a relation between subclinical hypothyroidism and peripheral arterial disease in women [24], and two case-control studies revealed an association between subclinical hypothyroidism and coronary artery disease in elderly women $[25,26]$. However, an important limitation of the above mentioned studies $[25,26]$ might have been that they included only women, and therefore gender-specific
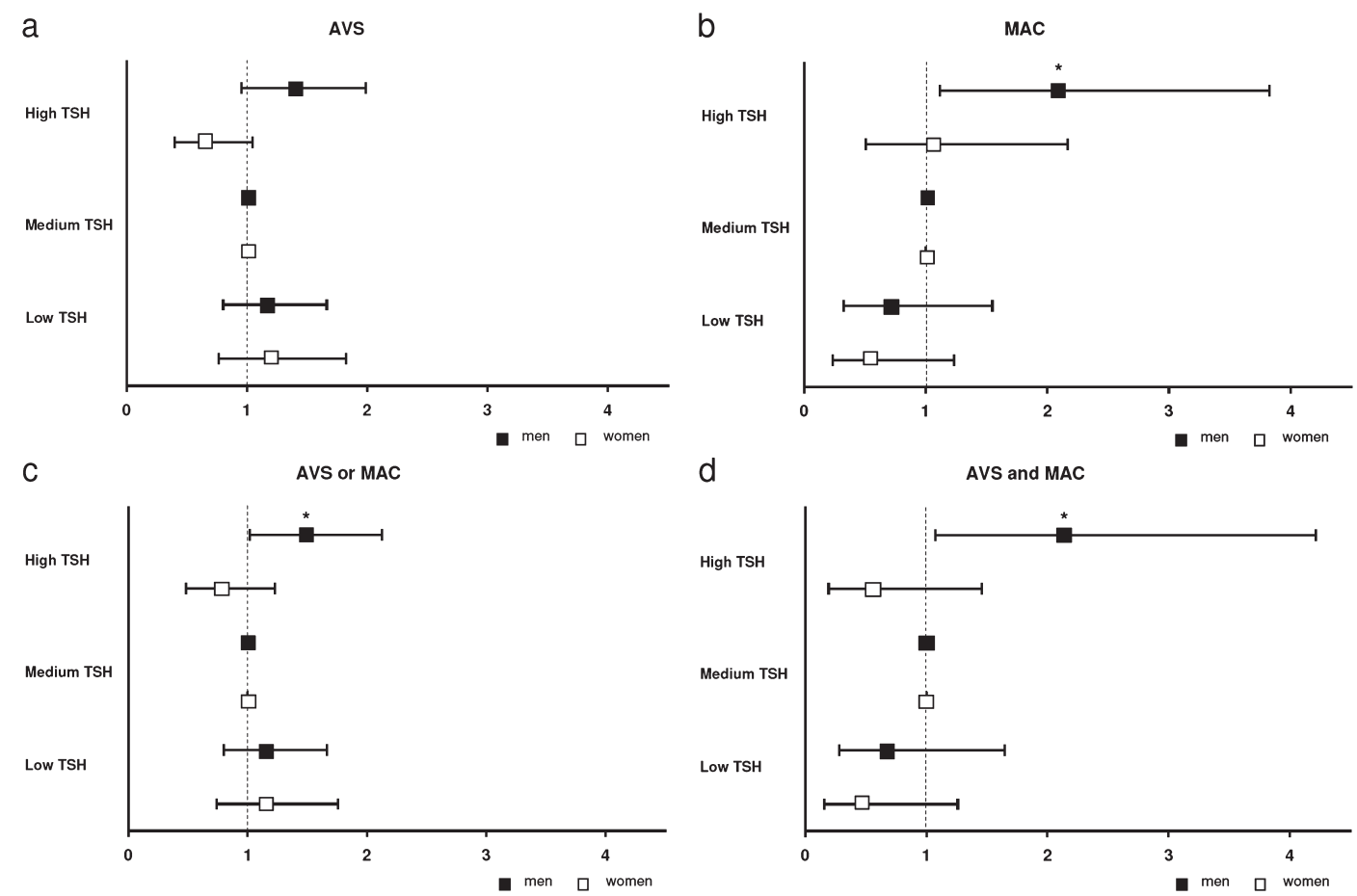

Fig. 2. a-d: The relation of serum TSH levels with AVS, MAC, AVS or MAC, and the combination of AVS and MAC with respect to gender

Odds ratio ( $\boldsymbol{\square})$ and 95 percent confidence-interval $(\longmapsto)$. Multivariate adjustments were made for age, BMI, pulse pressure, prior myocardial infarction, diabetes mellitus, serum fibrinogen, smoking status, education status, medication (ACE inhibitors, AT-II antagonists, statins) and functional thyroid status. Low TSH, $1^{\text {st }}$ sex-specific quintile; $<0.37 \mathrm{mIU} / \mathrm{L}$ in women and $<0.35 \mathrm{mIU} / \mathrm{L}$ in men; medium TSH, $2^{\text {nd }}$ to $4^{\text {th }}$ sex-specific quintile: $0.37-1.02 \mathrm{mIU} / \mathrm{L}$ in women and $0.35-0.92 \mathrm{mIU} / \mathrm{L}$ in men; high TSH, $5^{\text {th }}$ sex-specific quintile: $>1.02 \mathrm{mIU} / \mathrm{L}$ in women and $>0.92 \mathrm{mIU} / \mathrm{L}$ in men. ${ }^{*} \mathrm{p}<0.05$ versus medium TSH (binary logistic regression analysis). 
analyses have not been performed.

The reasons for observing an association between thyroid function and valve scerosis only in male participants of our study can only be an issue of speculation. One explanation could be that male gender per se is a strong risk factor for atherosclerotic diseases. Thus, higher susceptibility for heart valve sclerosis in men compared to women might be assumed. This is in line with several earlier studies that identified male gender as a risk factor for AVS $[1,2,27]$. Since female gender per se is associated with a decreased risk for valve sclerosis [2] it might be necessary to include a higher proportion of women to detect achieve statistical significant results. Thus, we cannot exclude that our analyses were underpowered for that purpose.

Several mechanisms may contribute to a possible association between a hypothyroid function state and atherosclerosis. First, there is a known link between thyroid failure and disturbances of lipid metabolism [28]. Second, hypothyroidism may be associated with hypertension [29]. Third, overt hypothyroidism has been reported to be accompanied by a hypercoagulable state $[30,31]$, and we cannot exclude an influence of other hemostatic properties such as elevated homocystein levels [31]. Finally, autoimmune thyroiditis, which is a common cause of hypothyroid function, may play an important role for the association with atherosclerosis. Autoimmune thyroiditis per se has been reported to be related to coronary heart disease $[25,26]$, but this could be not confirmed in others [19, 20,32]. However, such an influence is very unlikely, since inclusion of TPOAb status into the statistical models did not affect the final results. Since some of these potential mediators between hypothyroidism and valve sclerosis were considered as confounders in the present study, underestimation of the risk estimates might be discussed.

AVS and MAC are strong markers of cardiovascular and all-cause mortality $[5,11,12]$, respectively. Since in the present study there was an association between thyroid function and valve sclerosis already in the general population, such a relation might also be present in (subclinical) hypothyroid patients, and could even be of prognostic significance. Our results do not lead towards a recommendation for thyroid hormone treatment of subjects with low TSH levels aiming on prevention of atherosclerotic diseases, but they show clearly the need for further investigation on this issue in a clinical setting. Moreover, it might be reasonable to screen patients with known AVS or MAC for hypothyroidism, since hypothyroidism is a potentially modifiable risk factor.

\section{Study limitations and strengths}

Due to the cross-sectional nature of our study, the observed findings necessitate careful interpretation. At least in theory elevation of TSH might be also due to nonthyroidal illness. However, such a bias is highly unlikely since our data are taken from a sample of the normal population. Nevertheless, the large sample size, the availability of data on key risk factors, the wide range of age of participants and the consistency of our findings over a number of sensitivity analyzes are strengths of our study. Moreover, we were able to consider medication within the statistical models, which was not done by any comparable study.

In conclusion, there was an association between thyroid function and valvular sclerosis in this sample from the general population in men, but not in women. Males with high serum TSH levels had increased odds of MAC, AVS or MAC, and the combination of both. These findings may reflect an increased atherosclerotic state in affected subjects. They should be validated in prospective studies in (subclinical) hypothyroid patients.

\section{Acknowledgements}

The work is part of the Community Medicine Research net (CMR) of the University of Greifswald, Germany, which is funded by the Federal Ministry of Education and Research (grant no. ZZ9603), the Ministry of Cultural Affairs as well as the Social Ministry of the Federal State of Mecklenburg-West Pomerania. The CMR encompasses several research projects which share data from the population-based Study of Health in Pomerania (SHIP; http://www.medizin.unigreifswald.de/cm). The contribution to data collection made by field workers, technicians, interviewers, and computer assistants is gratefully acknowledged. This project was further supported by the German Research Foundation (DFG Vo 955/5-1). 


\section{References}

1. Agmon Y, Khandheria BK, Meissner I, Sicks JR, O'Fallon WM, Wiebers DO, Whisnant JP, Seward JB, Tajik AJ (2001) Aortic valve sclerosis and aortic atherosclerosis: different manifestations of the same disease? Insights from a population-based study. $\mathrm{J} \mathrm{Am}$ Coll Cardiol 38: 827-834.

2. Boon A, Cheriex E, Lodder J, Kessels F (1997) Cardiac valve calcification: characteristics of patients with calcification of the mitral annulus or aortic valve. Heart 78: 472-474.

3. Sell S, Scully RE (1965) Aging Changes in the Aortic and Mitral Valves. Histologic and Histochemical Studies, with Observations on the Pathogenesis of Calcific Aortic Stenosis and Calcification of the Mitral Annulus. Am J Pathol 46: 345-365.

4. Kizer JR, Wiebers DO, Whisnant JP, Galloway JM, Welty TK, Lee ET, Best LG, Resnick HE, Roman MJ, Devereux RB (2005) Mitral annular calcification, aortic valve sclerosis, and incident stroke in adults free of clinical cardiovascular disease: the Strong Heart Study. Stroke 36: 2533-2537.

5. Otto CM, Lind BK, Kitzman DW, Gersh BJ, Siscovick DS (1999) Association of aortic-valve sclerosis with cardiovascular mortality and morbidity in the elderly. N Engl J Med 341: 142-147.

6. Allison MA, Cheung $\mathrm{P}$, Criqui $\mathrm{MH}$, Langer RD, Wright CM (2006) Mitral and aortic annular calcification are highly associated with systemic calcified atherosclerosis. Circulation 113: 861-866.

7. Klein I, Ojamaa K (2001) Thyroid hormone and the cardiovascular system. $N$ Engl J Med 344: 501-509.

8. Biondi B, Klein I (2004) Hypothyroidism as a risk factor for cardiovascular disease. Endocrine 24: 1-13.

9. Perk M, O’Neill BJ (1997) The effect of thyroid hormone therapy on angiographic coronary artery disease progression. Can J Cardiol 13: 273-276.

10. Monzani F, Caraccio N, Kozakowa M, Dardano A, Vittone F, Virdis A, Taddei S, Palombo C, Ferrannini E (2004) Effect of levothyroxine replacement on lipid profile and intima-media thickness in subclinical hypothyroidism: a double-blind, placebo-controlled study. J Clin Endocrinol Metab 89: 2099-2106.

11. Fox CS, Vasan RS, Parise H, Levy D, O’Donnell CJ, D’Agostino RB, Benjamin EJ (2003) Mitral annular calcification predicts cardiovascular morbidity and mortality: the Framingham Heart Study. Circulation 107: 1492-1496.

12. Barasch E, Gottdiener JS, Marino Larsen EK, Chaves PH, Newman AB (2006) Cardiovascular morbidity and mortality in community-dwelling elderly individuals with calcification of the fibrous skeleton of the base of the heart and aortosclerosis (The Cardiovascular Health Study). Am J Cardiol 97: 1281-1286.
13. Völzke H, Schwahn C, Wallaschofski H, Dörr M (2007) The association of thyroid dysfunction with allcause and circulatory mortality: Is there a causal relationship? J Clin Endocrinol Metab 92: 2421-2429.

14. Parle JV, Maisonneuve P, Sheppard MC, Boyle P, Franklyn JA (2001) Prediction of all-cause and cardiovascular mortality in elderly people from one low serum thyrotropin result: a 10-year cohort study. Lancet 358: 861-865.

15. Gussekloo J, van Exel E, de Craen AJ, Meinders AE, Frolich M, Westendorp RG (2004) Thyroid status, disability and cognitive function, and survival in old age. Jama 292: 2591-2599.

16. Atar S, Jeon DS, Luo H, Siegel RJ (2003) Mitral annular calcification: a marker of severe coronary artery disease in patients under 65 years old. Heart 89: 161-164.

17. Adler Y, Shohat-Zabarski R, Vaturi M, Shapira Y, Ehrlich S, Jortner R, Assali A, Zonshin A, Sagie A (1998) Association between mitral annular calcium and aortic atheroma as detected by transesophageal echocardiographic study. Am J Cardiol 81: 784-786.

18. Barasch E, Gottdiener JS, Larsen EK, Chaves PH, Newman AB, Manolio TA (2006) Clinical significance of calcification of the fibrous skeleton of the heart and aortosclerosis in community dwelling elderly. The Cardiovascular Health Study (CHS). Am Heart J 151: 39-47.

19. Heinonen OP, Gordin A, Aho K, Punsar S, Pyorala K, Puro K (1972) Symptomless autoimmune thyroiditis in coronary heart-disease. Lancet 1: 785-786.

20. Miura S, Iitaka M, Suzuki S, Fukasawa N, Kitahama S, Kawakami Y, Sakatsume Y, Yamanaka K, Kawasaki S, Kinoshita S, Katayama S, Shibosawa T, Ishii J (1996) Decrease in serum levels of thyroid hormone in patients with coronary heart disease. Endocr J 43: 657663.

21. Völzke H, Robinson DM, Schminke U, Ludemann J, Rettig R, Felix SB, Kessler C, John U, Meng W (2004) Thyroid function and carotid wall thickness. J Clin Endocrinol Metab 89: 2145-2149.

22. Bruckert E, Giral P, Chadarevian R, Turpin G (1999) Low free-thyroxine levels are a risk factor for subclinical atherosclerosis in euthyroid hyperlipidemic patients. J Cardiovasc Risk 6: 327-331.

23. Hak AE, Pols HA, Visser TJ, Drexhage HA, Hofman A, Witteman JC (2000) Subclinical hypothyroidism is an independent risk factor for atherosclerosis and myocardial infarction in elderly women: the Rotterdam Study. Ann Intern Med 132: 270-278.

24. Powell JT, Carter G, Woolcock N, Greenhalgh RM, Fowler PB, Zadeh JA (1991) The relationship between serum cholesterol and serum thyrotropin in women with peripheral arterial disease. Ann Clin Biochem 28 
(Pt 3): 318-319.

25. Tieche M, Lupi GA, Gutzwiller F, Grob PJ, Studer H, Burgi H (1981) Borderline low thyroid function and thyroid autoimmunity. Risk factors for coronary heart disease? Br Heart J 46: 202-206.

26. Dean JW, Fowler PB (1985) Exaggerated responsiveness to thyrotrophin releasing hormone: a risk factor in women with coronary artery disease. $\mathrm{Br} \mathrm{Med} J$ (Clin Res Ed) 290: 1555-1561.

27. Mohler ER, Sheridan MJ, Nichols R, Harvey WP, Waller BF (1991) Development and progression of aortic valve stenosis: atherosclerosis risk factors - a causal relationship? A clinical morphologic study. Clin Cardiol 14: 995-999.

28. Luboshitzky R, Aviv A, Herer P, Lavie L (2002) Risk factors for cardiovascular disease in women with subclinical hypothyroidism. Thyroid 12: 421-425.
29. Fommei E, Iervasi G (2002) The role of thyroid hormone in blood pressure homeostasis: evidence from short-term hypothyroidism in humans. J Clin Endocrinol Metab 87: 1996-2000.

30. Chadarevian R, Bruckert E, Giral P, Turpin G (1999) Relationship between thyroid hormones and fibrinogen levels. Blood Coagul Fibrinolysis 10: 481-486.

31. Nedrebo BG, Ericsson UB, Nygard O, Refsum H, Ueland PM, Aakvaag A, Aanderud S, Lien EA (1998) Plasma total homocysteine levels in hyperthyroid and hypothyroid patients. Metabolism 47: 89-93.

32. Vanderpump MP, Tunbridge WM, French JM, Appleton D, Bates D, Clark F, Grimley Evans J, Rodgers H, Tunbridge F, Young ET (1996) The development of ischemic heart disease in relation to autoimmune thyroid disease in a 20-year follow-up study of an English community. Thyroid 6: 155-160. 